\title{
A Method for Evaluating the Risk of Exposure to COVID-19 by Using Location Data
}

\section{Un Método para la Evaluación del Riesgo de Exposición al Virus de COVID-19 Usando los Datos de Locación}

Gerardo Mendizabal-Ruiz

Universidad de Guadalajara

\begin{abstract}
One of the main reasons for the widespread dissemination of COVID-19 is that many infected people are asymptomatic. Consequently, they likely spread the virus to other people as they continue their everyday life. This emphasizes the importance for targeting high-risk groups for the diagnosis of COVID-19 (with real-time PCR techniques). However, the availability of the necessary technology and resources may be limited in certain towns, cities or countries. Thus, the challenge is to determine a criterion in order to prioritize the suspected cases most in need of testing. The aim of the present study was to develop a method for evaluating the risk of exposure to COVID-19 infection based on geolocation data. The risk is expressed as a score that will be instrumental in optimally applying the COVID-19 test to suspected cases representing the highest probability of exposure. It can be easily and quickly implemented with easily accessible open source tools. A simulation was herein conducted with data from four people, assigning infection to one of them. The results show the feasibility of assessing the risk of exposure with the new methodology. Additionally, the data obtained might provide insights into the sometimes complicated patterns of virus propagation.
\end{abstract}

KEYwords: Risk assessment, COVID-19, location data. 


\section{RESUMEN}

Una de las principales razones del esparcimiento del COVID-19 es que muchas de las personas infectadas son asintomáticas. Así entonces, al continuar con su vida diaria estas personas contagiadas son susceptibles a contagiar el virus a otras personas sin siquiera imaginarlo. Actualmente el diagnostico de COVID-19 se lleva a cabo usando técnicas de PCR en tiempo real. Sin embargo, la disponibilidad de dichas pruebas puede ser limitada en algunos países o ciudades. En este sentido determinar un criterio que permita definir a cuáles casos sospechosos deben de ser aplicada la prueba resulta un reto importante. En este artículo se presenta un método que permite evaluar el riesgo de exposición de una persona al COVID-19 que está basado en el uso de los datos locación. El método propuesto puede ser rápida y fácilmente implementada utilizando herramientas de código abierto existentes actualmente. El método propuesto fue probado utilizando datos de cuatro personas simulando a uno de ellos como portador del virus. Los resultados muestran la factibilidad del método propuesto para evaluar el riesgo de exposición. Además, los datos que se obtienen pueden ser potencialmente utilizados para un mejor entendimiento de los patrones de dispersión del virus.

KEYWORDS: Evaluación de riesgo, COVID-19, datos de localización.

\section{Corresponding author}

TO: Eduardo Gerardo Mendizabal Ruiz

INSTITUTION: Universidad de Guadalajara

ADDRESS: Av. Juárez \#976, Col. Centro, C. P. 44100,

Guadalajara, Jalisco, México

E-MAIL: gerardo.mendizabal@academicos.udg.mx

\section{Received:}

11 May 2020

Accepted:

24 July 2020 


\section{INTRODUCTION}

COVID-19 is spreading across the world at an alarming rate, making the global outbreak a significant public health problem ${ }^{[1]}$. One of the main reasons for the large-scale spread of COVID-19 is that an estimated $80 \%$ of carriers are asymptomatic or have mild symptoms ${ }^{[2]}$. Thus, many infected people could unknowingly spread the virus ${ }^{[3]}{ }^{[4]}$. Since the COVID-19 virus remains on surfaces and in aerosols for many days under certain conditions, people may get infected by touching contaminated objects long after the carrier has departed ${ }^{[5]}$.

Consequently, opportune testing of suspected cases is crucial for clinical management and outbreak control. According to the World Health Organization, the decision to test an individual should be based on clinical (symptoms) and epidemiological factors (contact with a confirmed case) associated with the likelihood of infection ${ }^{[6]}$.

For suspected cases, nucleic acid amplification analysis (RT-PCR) ${ }^{[6]}$ is recommended for COVID-19 testing. In some towns, cities or countries, unfortunately, the resources for such tests may be limited. Therefore, a criterion is needed to determine when to perform a test once the growing number of cases begins to surpass the resources available. Moreover, in the event that people could assure themselves of a high risk of exposure to infection, they would be more prone to self-quarantine even if they are asymptomatic.

The aim of the present study was to develop a method for evaluating the risk of exposure to COVID19 infection based on geolocation data. The risk is expressed as a score that will be instrumental in optimizing the application of the COVID-19 test to suspected cases representing the highest probability of exposure. To implement the method, a webpage is created for uploading the geolocation data of con- firmed COVID-19 cases of the previous days. The geolocation data of a suspected case is then entered into the same webpage in order to calculate an exposure risk score. The latter is computed based on the number of places where one or more confirmed cases and the suspected case were near each other within overlapping periods. A time window after the departure of the confirmed cases is contemplated to reflect the virus survival time.

\section{MATERIALS AND METHODS}

\section{Geolocation data}

Modern smartphones have a variety of sensors capable of registering the coordinates, accompanied with timestamps, of the routes taken and places visited by the user. Such data could be saved as a JSON file to create a history of geolocation data, considering two attributes of interest (AOI):

- location: the latitude and longitude of a place visited by the user.

- duration: the length of time spent at a given place calculated from startTimestampMS and endTimestamMs, corresponding to the arrival and departure times, respectively.

\section{Google location data}

Google allows owners of a device (e.g., a smartphone) to request the history of location data at https://www.google.com/maps/timeline. The data is sent to the e-mail account of the user in the form of a zip file containing a folder for each year that Google has collected this information. Location data for each month is stored in a JSON file, which contains data for every day of the month in the form of data objects. The placeVisit objects register the places where the user stayed for some period of time. From these data-objects, the AOI can be retrieved. 


\section{Registering confirmed cases}

A person confirmed to be infected with COVID-19 should provide the location data available in a JSON file. Subsequently, an authorized person (most likely a health authority in charge of the system) uploads the file into a web service offering cloud computing services. The web service reads and parses the JSON data corresponding to the AOI of the previous $\mathrm{N}$ days by analyzing each placeVisit object in the file. The values are registered into a relational database, storing only the places and times but not the identity of the confirmed case to conserve the confidentiality of the data. Finally, it is possible to make queries by entering data of suspected cases into the web service.

\section{Computing the exposure risk score}

The JSON data of a person who wants to evaluate his or her risk of exposure is utilized similarly, extracting all the placeVisit objects within the last M days. The proposed method is based on the hypothesis that a person (suspected case) has a determined risk of COVID-19 infection whenever they were at the same place of a confirmed case in the same time lapse (or within a given time window following the departure of the latter).

Let $A T_{S}, D T_{S}, A T_{C}$ and $D T_{C}$ be the arrival and departure times of the suspected and confirmed cases, respectively. Examples are illustrated in Figure 1 of suspected cases at high, medium and low risk of exposure, depending on their arrival and departure times to a specific place. If there is an overlap of periods between the suspected and infected cases, a high risk of infection is assigned. When the arrival time of the suspected case is after the departure time of the confirmed case, the virus survival time must be taken into account. In the event that the arrival time is within the window of virus survival on surfaces, a medium risk of infection exists ${ }^{[5]}$. If the suspected case has a departure time before the arrival of the confirmed case or an arrival time after the virus survival time, it is possible to designate low risk. A Sigmoid function is employed to compute a risk score $\mathrm{Rk}$ for each place $\mathrm{k}$ of coincidence of a suspected case with a confirmed case within the defined time window, depending on the difference between the arrival time of the suspected case and the departure time of the confirmed case (i.e., $\Delta\left(A T_{S}-D T_{C}\right)$ :

$$
R_{k}=\left\{\begin{array}{lr}
\frac{1}{1+\exp ^{-\lambda}(\mu-\Delta)} & \text { if } A T_{s}>D T_{c} \\
1 & \text { Otherwise }
\end{array}\right.
$$

Where $\mu$ is the value in hours representing the difference between the arrival time of the suspected case and the departure time of the confirmed case that gives a score of 0.5 . The real difference $(\Delta)$ is subtracted from $\mu$. The parameter $\lambda$ is a constant that determines the slope of the transient region of the Sigmoid curve, allowing for control over which values of $\Delta$ converge to a risk score of 0 . As the difference between the departure time of the confirmed case and the arrival time of the suspected case increases, the risk score for the corresponding place will decrease at a rate dependent on the values of $\lambda$ and $\mu$.

Finally, a total risk score $(R)$ is computed by adding the risk score of all the places where the suspected case and any of the confirmed cases were near according to the following rules:

- The latitude and longitude of the place visited by the suspected case are equal to the latitude and longitude of the place visited by the confirmed case.

- The numerical value of the arrival time of the suspected case is less than that of the departure time of the confirmed case, and the value of the departure time of the suspected case is greater than the arrival time of the confirmed case (examples 1 and 2 in Fig. 1); or the value of the arrival time of the suspected case is greater than the 
arrival time of the confirmed case and less than or equal to the departure time of the confirmed case plus a given range $\Delta T$ representing the virus survival time (examples 3 and 4 in Fig. 1).

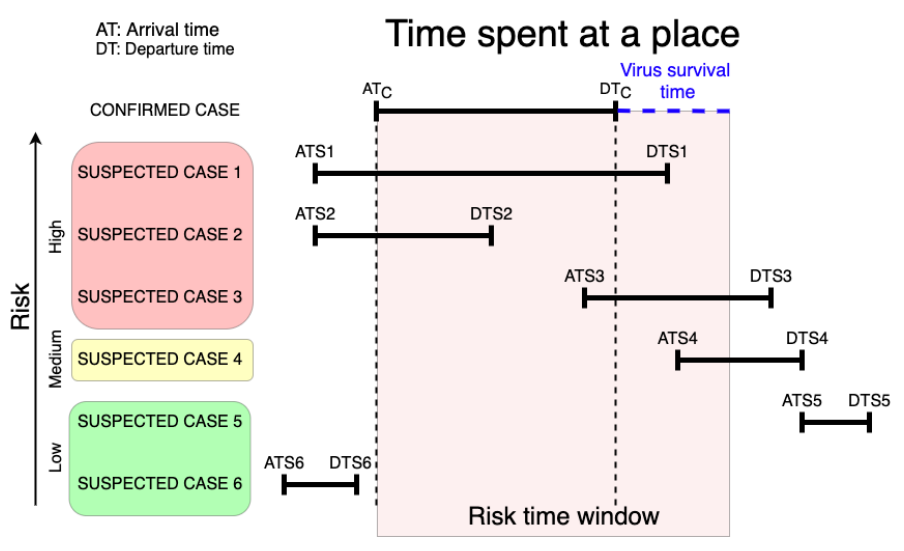

FIGURE 1. Diagram of the risk of infection based on the arrival and departure times of confirmed and suspected cases.

\section{RESULTS AND DISCUSSION}

The present method was implemented by using Python 3.7 in the Flask web development framework [7]. The geolocation data employed was extracted from the JSON files downloaded from Google and stored in a MySql database. The places where a suspected case was at risk of exposure are indicated in a map via folium ${ }^{[8]}$. The system was deployed into a virtual environment by means of Ubuntu 16.04 .

The method was evaluated by a simulation based on data from four people (A, B, C and D) during 20 days. The four healthy individuals signed informed consent formats and downloaded the data from the Google Takeout service (https://takeout.google.com/). They voluntarily provided the downloaded data for the sake of the simulation.

Persons A, B and C work in the same building but do not necessarily have exactly the same schedule. A and $B$ met in a mall for 3 hours on a particular day. A and D met at a party on one of the days under study. For this exercise, $\mathrm{A}$ is assumed to be infected throughout the period being analyzed. For the sigmoid function that determines the exposure risk score during the virus survival time, the values of $\lambda=0.1$ and $\mu=12$ were adopted. These values were defined to generate a score near 0.5 and 0 when the time elapsed following the departure of the confirmed case was about $12 \mathrm{~h}$ and 24 h, respectively.

Risk scores were assigned for each place at which person $\mathrm{B}$ was near person A within the time window (Table 1).

TABLE 1. Exposure risk data for person $B$.

\begin{tabular}{|c|c|c|c|c|c|}
\hline$k$ & $A T_{c}$ & $D T_{c}$ & $A T_{s}$ & $D T_{s}$ & $R_{k}$ \\
\hline 1 & $3 / 2 / 209: 10$ & $3 / 2 / 2013: 21$ & $3 / 2 / 209: 09$ & $3 / 2 / 2015: 35$ & 1.00 \\
\hline 2 & $3 / 3 / 208: 26$ & $3 / 3 / 2013: 31$ & $3 / 4 / 208: 57$ & $3 / 4 / 2016: 05$ & 0.32 \\
\hline 3 & $3 / 4 / 208: 27$ & $3 / 4 / 2013: 41$ & $3 / 4 / 208: 57$ & $3 / 4 / 2016: 05$ & 1.00 \\
\hline 4 & $3 / 5 / 208: 36$ & $3 / 5 / 2011: 12$ & $3 / 5 / 2016: 37$ & $3 / 5 / 2016: 44$ & 0.66 \\
\hline 5 & $3 / 9 / 208: 22$ & $3 / 9 / 2013: 19$ & $3 / 9 / 2010: 06$ & $3 / 9 / 2010: 42$ & 1.00 \\
\hline 6 & $3 / 9 / 208: 22$ & $3 / 9 / 2013: 19$ & $3 / 10 / 2010: 25$ & $\begin{array}{l}3 / 10 / 20 \\
14: 38\end{array}$ & 0.29 \\
\hline 7 & $\begin{array}{l}3 / 10 / 20 \\
7: 18\end{array}$ & $3 / 10 / 2012: 39$ & $3 / 10 / 2010: 25$ & $\begin{array}{l}3 / 10 / 20 \\
14: 38\end{array}$ & 1.00 \\
\hline 8 & $\begin{array}{l}3 / 10 / 20 \\
7: 18\end{array}$ & $3 / 10 / 2012: 39$ & $3 / 11 / 209: 03$ & $\begin{array}{l}3 / 11 / 20 \\
14: 13\end{array}$ & 0.30 \\
\hline 9 & $\begin{array}{l}3 / 11 / 20 \\
8: 24\end{array}$ & $3 / 11 / 2013: 10$ & $3 / 11 / 209: 03$ & $\begin{array}{l}3 / 11 / 20 \\
14: 13 \\
\end{array}$ & 1.00 \\
\hline 10 & $\begin{array}{l}3 / 11 / 20 \\
8: 24\end{array}$ & $3 / 11 / 2013: 10$ & $3 / 12 / 209: 18$ & $3 / 12 / 209: 30$ & 0.31 \\
\hline 11 & $\begin{array}{l}3 / 12 / 20 \\
7: 52\end{array}$ & $3 / 12 / 208: 57$ & $3 / 12 / 209: 18$ & $3 / 12 / 209: 30$ & 0.76 \\
\hline 12 & $\begin{array}{l}3 / 12 / 20 \\
7: 52\end{array}$ & $3 / 12 / 208: 57$ & $3 / 12 / 2014: 49$ & $\begin{array}{l}3 / 12 / 20 \\
15: 07\end{array}$ & 0.65 \\
\hline 13 & $\begin{array}{l}3 / 13 / 20 \\
12: 39 \\
\end{array}$ & $3 / 13 / 2013: 36$ & $3 / 13 / 2010: 19$ & $\begin{array}{l}3 / 13 / 20 \\
14: 15 \\
\end{array}$ & 1.00 \\
\hline 14 & $\begin{array}{l}3 / 17 / 20 \\
12: 42\end{array}$ & $3 / 17 / 2013: 48$ & $3 / 18 / 2010: 11$ & $\begin{array}{l}3 / 18 / 20 \\
10: 17\end{array}$ & 0.30 \\
\hline 15 & $\begin{array}{l}3 / 19 / 20 \\
10: 11\end{array}$ & $3 / 19 / 2013: 32$ & $3 / 19 / 209: 39$ & $\begin{array}{l}3 / 19 / 20 \\
13: 34\end{array}$ & 1.00 \\
\hline 16 & $\begin{array}{l}3 / 19 / 20 \\
14: 07\end{array}$ & 3/19/20 14:19 & $3 / 19 / 2014: 08$ & $\begin{array}{l}3 / 19 / 20 \\
14: 17\end{array}$ & 1.00 \\
\hline & & & & Risk Score & 11.59 \\
\hline
\end{tabular}

In the event that the arrival time of the suspected case was after the departure time of the confirmed case but within the virus survival time, the score is less than one. A map denoting two infection foci 
(Figure 2) identifies the places where person B was at risk of exposure (the workplace and the mall). The total risk score for person $\mathrm{B}$ is $R=11.59$, which is considerably high in the current scheme.

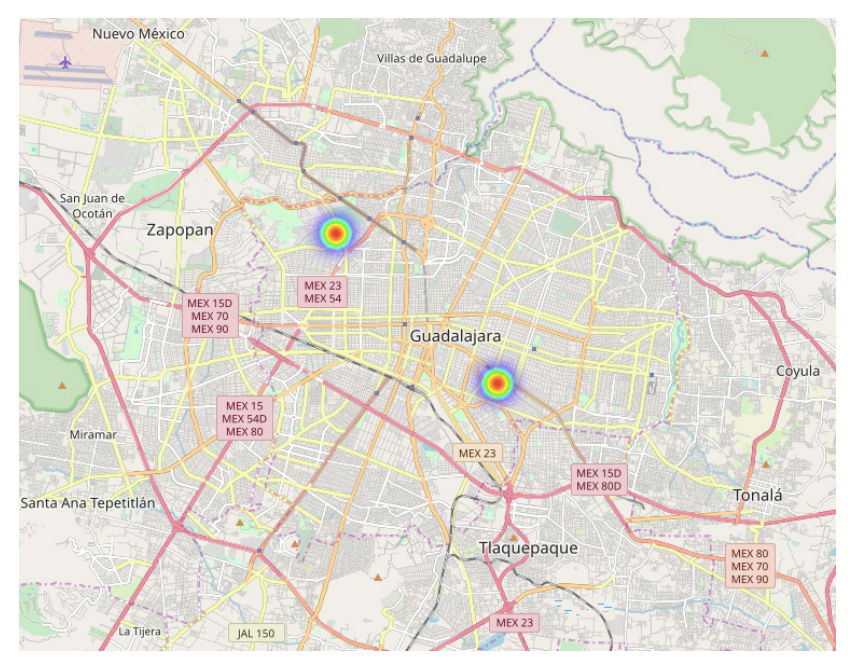

FIGURE 2. A map highlighting the places where person $B$ was at risk of exposure to infection.

Risk scores were designated for each place where person $\mathrm{C}$ was near person $\mathrm{A}$ within the time window (Table 2). As with person $B$, some of the place scores are less than one (for the aforementioned reason). The first two scores ( $k=1$ and $k=2$ ) correspond to the same period for the confirmed case.

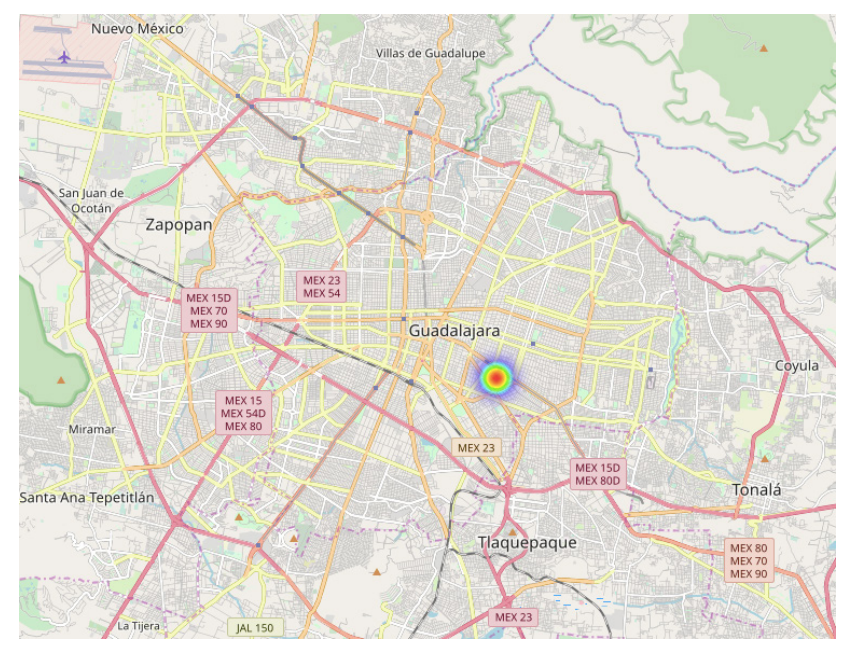

FIGURE 3. A map portraying the place where person $C$ was at risk of exposure to infection.
TABLE 2. Exposure risk data for person $C$.

\begin{tabular}{|r|c|c|c|c|c|}
\hline$k$ & $A T_{C}$ & $D T_{c}$ & $A T_{s}$ & $D T_{s}$ & $R_{k}$ \\
\hline 1 & $3 / 2 / 209: 10$ & $3 / 2 / 2013: 21$ & $3 / 2 / 207: 35$ & $3 / 2 / 209: 20$ & 1.00 \\
\hline 2 & $3 / 2 / 209: 10$ & $3 / 2 / 2013: 21$ & $3 / 2 / 2010: 50$ & $3 / 2 / 2016: 03$ & 1.00 \\
\hline 3 & $3 / 2 / 209: 10$ & $3 / 2 / 2013: 21$ & $3 / 3 / 207: 43$ & $3 / 3 / 209: 19$ & 0.35 \\
\hline 4 & $3 / 3 / 208: 26$ & $3 / 3 / 2013: 31$ & $3 / 3 / 207: 43$ & $3 / 3 / 209: 19$ & 1.00 \\
\hline 5 & $3 / 3 / 208: 26$ & $3 / 3 / 2013: 31$ & $3 / 4 / 207: 48$ & $3 / 4 / 2013: 53$ & 0.35 \\
\hline 6 & $3 / 4 / 208: 27$ & $3 / 4 / 2013: 41$ & $3 / 4 / 207: 48$ & $3 / 4 / 2013: 53$ & 1.00 \\
\hline 7 & $3 / 4 / 208: 27$ & $3 / 4 / 2013: 41$ & $3 / 5 / 207: 53$ & $3 / 5 / 208: 44$ & 0.35 \\
\hline 8 & $3 / 5 / 208: 36$ & $3 / 5 / 2011: 12$ & $3 / 5 / 207: 53$ & $3 / 5 / 208: 44$ & 1.00 \\
\hline 9 & $3 / 5 / 208: 36$ & $3 / 5 / 2011: 12$ & $3 / 5 / 2016: 48$ & $3 / 5 / 2016: 59$ & 0.65 \\
\hline 10 & $3 / 6 / 2010: 42$ & $3 / 6 / 2014: 18$ & $3 / 6 / 2016: 52$ & $3 / 6 / 2019: 14$ & 0.72 \\
\hline 11 & $3 / 9 / 208: 22$ & $3 / 9 / 2013: 19$ & $3 / 9 / 207: 53$ & $3 / 9 / 209: 42$ & 1.00 \\
\hline 12 & $3 / 9 / 208: 22$ & $3 / 9 / 2013: 19$ & $3 / 10 / 207: 39$ & $3 / 10 / 208: 44$ & 0.35 \\
\hline 13 & $3 / 10 / 207: 18$ & $3 / 10 / 2012: 39$ & $3 / 10 / 207: 39$ & $3 / 10 / 208: 44$ & 1.00 \\
\hline 14 & $3 / 10 / 207: 18$ & $3 / 10 / 2012: 39$ & $3 / 11 / 207: 37$ & $3 / 11 / 208: 41$ & 0.33 \\
\hline 15 & $3 / 11 / 208: 24$ & $3 / 11 / 2013: 10$ & $3 / 11 / 207: 37$ & $3 / 11 / 208: 41$ & 1.00 \\
\hline 16 & $3 / 11 / 208: 24$ & $3 / 11 / 2013: 10$ & $3 / 12 / 207: 49$ & $3 / 12 / 208: 48$ & 0.34 \\
\hline 17 & $3 / 12 / 207: 52$ & $3 / 12 / 208: 57$ & $3 / 12 / 207: 49$ & $3 / 12 / 208: 48$ & 1.00 \\
\hline 18 & $3 / 12 / 207: 52$ & $3 / 12 / 208: 57$ & $3 / 12 / 20$ & $3 / 12 / 20$ & 0.63 \\
\hline 19 & $3 / 13 / 2012: 39$ & $3 / 13 / 2013: 36$ & $3 / 13 / 20$ & $3 / 13 / 20$ & 0.73 \\
\hline & & & $15: 50$ & $16: 42$ & 13.79 \\
\hline
\end{tabular}

During that time, person $\mathrm{C}$ left the building for some time and came back later. The total risk score is even greater for person $\mathrm{C}(R=13.79)$ than person $\mathrm{B}$.

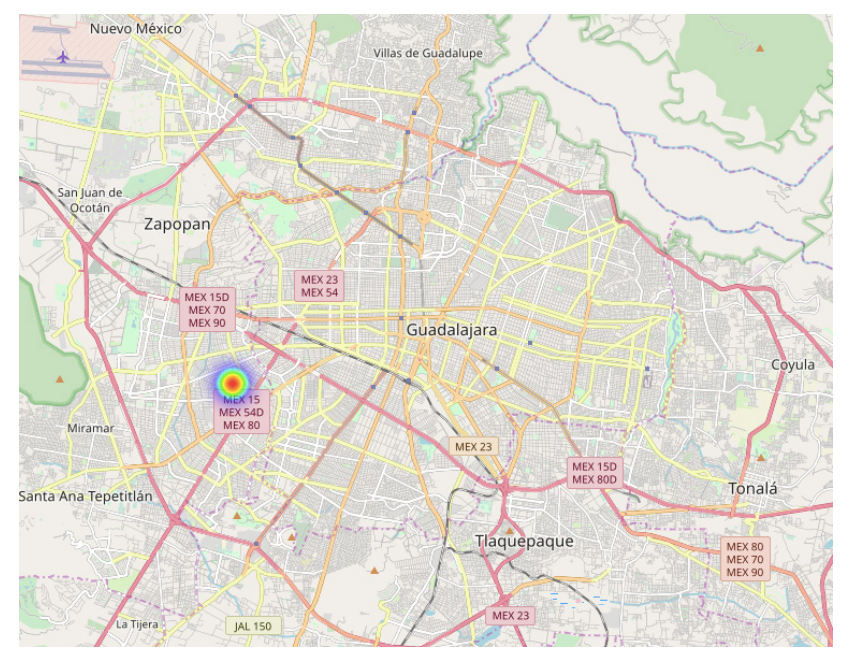

FIGURE 4. A map depicting the place where person D was at risk of exposure to infection. 
A map is shown with only one place highlighted (the workplace), at which person $C$ was exposed to the risk of infection (Figure 3). A risk score was assigned for a single place and time, representing the occasion person A and person D were at the same party (Table 3).

TABLE 3. Exposure risk data for person $D$.

\begin{tabular}{|c|c|c|c|c|c|}
\hline$k$ & $A T_{c}$ & $D T_{c}$ & $A T_{s}$ & $D T_{s}$ & $R_{k}$ \\
\hline 1 & $3 / 12 / 2015: 14$ & $3 / 12 / 2019: 33$ & $3 / 12 / 2015: 01$ & $3 / 12 / 2019: 16$ & 1 \\
\hline & & & & Risk Score & 1.00 \\
\hline
\end{tabular}

The risk score is $\mathrm{R}=1$ because there was only one occurrence. A map depicts the single place (a party) of the exposure of person $\mathrm{D}$ to the risk of infection (Figure 4).

The present results demonstrate that the proposed model can provide reliable exposure risk scores automatically, evidencing the feasibility of its implementation. The computed risk of exposure together with an analysis of the places and circumstances involved (with a risk score $>0$ ) may be useful for determining whether a person should be given a PCR-based test. For example, person $\mathrm{D}$ has a risk score of 1 due to being in the same place as the confirmed case for only $4 \mathrm{~h}$ on one occasion. Thus, he or she is probably not a candidate for testing if asymptomatic, since the time spent at the same place with an infected person was relatively short. However, in the event that person $\mathrm{D}$ shows symptoms, he or she is a likely candidate for testing, considering his proximity to a confirmed case. Persons B and C, on the other hand, are good candidates for PCR testing even if they have no symptoms because of sharing the same space with an infected person on repeated occasions for long periods of time.

An obvious limitation of the proposed model is the need for geolocation data. Although this information can be requested from the Google Takeout service, it will probably not be available for all the confirmed and suspected cases. The owner of the mobile device may not have configured a Google account in their mobile device or the location feature might be turned off.

A plausible alternative is the incorporation of a webbased questionnaire or interactive map allowing people to manually enter the locations of places visited and the corresponding times. Nevertheless, the manually entered information has the risk of being less accurate than the data obtained with the Google location files.

\section{Implementation issues}

There are two important issues to be considered for the implementation of the current methodology. Firstly, the tracking of user locations records very sensitive data. Secondly, the possibility of entering false information into the system must be confronted. Consequently, the proposed method should be implemented by a central health authority (HA), who could assure the validity of the data entered into the database and the anonymity of the users. The procedure for logging data into the system is illustrated with a flow diagram (Figure 5).

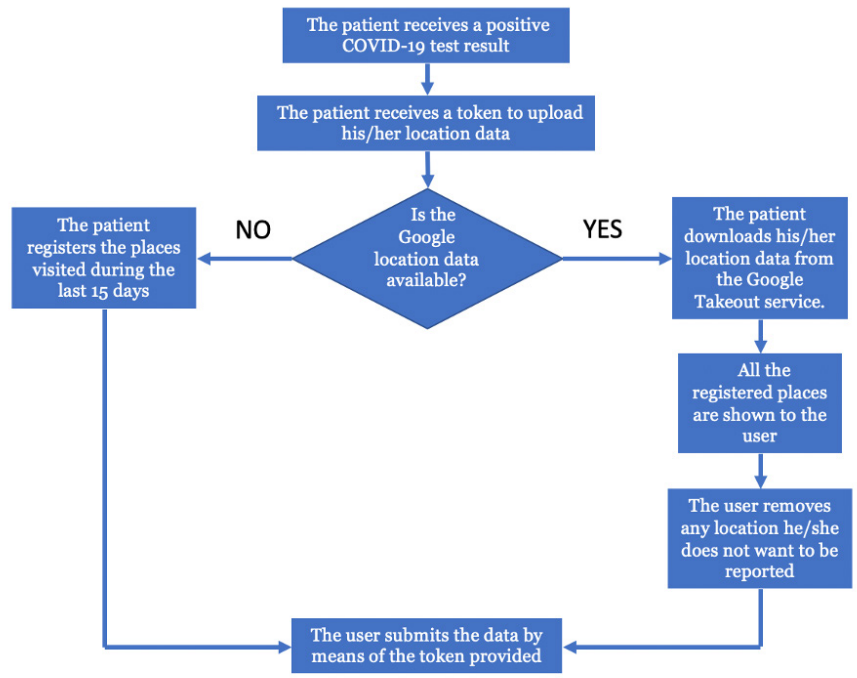

FIGURE 5. A flow diagram of the procedure for logging data into the system. 
It is essential to emphasize that the computation of risk scores does not involve any information related to the owner of the device (e.g., smartphone), such as his/ her name, age, gender or address. Since public trust in the anonymity of the data collection procedure is crucial, the procedure for registering data must automatically discard any existing confidential information before uploading files to the database.

According to the proposed model, the right to upload data to the system requires a token provided by the HA to the confirmed case at the time he/she receives a positive diagnosis. The token will be generated independently of patient identity information to assure the anonymity of the data. If the confirmed case is connected with the Google Takeout service, he/she can download and review the data. The only factor that could possibly reveal the identity of the owner of the device is the location data itself. Therefore, the data collection procedure has to include an option for the interested party to remove any sensitive location data (e.g., the location of residence). After making any necessary adjustments, the user will upload the data into the system.

\section{CONCLUSIONS}

Quarantine and social distancing are recommended measures for helping to contain the epidemic [2]. However, it may be complicated to impose quarantine over long periods of time since the personal and global economy is affected. Hence, a method was herein developed to confront the challenge of controlling the spread of the virus and prioritize COVID-19 testing when resources are limited.

Moreover, the information collected with the proposed procedure could lead to a better understanding of the patterns of dissemination of the virus based on the identification of the most critical places and times involved in infection. This might result in improved models of prediction for use in containing the spread of viruses. 


\section{REFERENCES}

[1] Lai CC, Shih TP, Ko WC, Tang HJ, Hsueh PR. Severe acute respiratory syndrome coronavirus 2 (SARS-CoV-2) and corona virus disease-2019 (COVID-19): the epidemic and the challenges. International Journal of Antimicrobial Agents. 2020;55(3):105924. https://doi.org/10.1016/j.ijantimicag.2020.105924

[2] Anderson RM, Heesterbeek H, Klinkenberg D, Hollingsworth TD. How will country-based mitigation measures influence the course of the COVID-19 epidemic? The Lancet. 2020;395(10228):931-934. https://doi.org/10.1016/S0140-6736(20)30567-5

[3] Hu Z, Song C, Xu C, Jin G, Chen Y, Xu X, Ma H, Chen W, Lin Y, Zheng Y, Wang J, Hu Z, Yi Y, Shen H. Clinical characteristics of 24 asymptomatic infections with COVID-19 screened among close contacts in Nanjing, China. Science China Life Sciences. 2020;63:706-711. https://doi.org/10.1007/s11427-020-1661-4

[4] Bai Y, Yao L, Wei T, Tian F, Jin DY, Chen L, Wang M. Presumed asymptomatic carrier transmission of COVID-19. JAMA. 2020;323(14):1406-7. https://doi.org/10.1001/jama.2020.2565
[5] van Doremalen N, Bushmaker T, Morris DH, Holbrook MG, Gamble A, Williamson BN, Tamin A, Harcourt JL, Thornburg NJ, Gerber SI, Lloyd-Smith JO. Aerosol and surface stability of SARS-CoV-2 as compared with SARS-CoV-1. New England Journal of Medicine. 2020;382(16) 1564-7. https://doi.org/10.1056/NEJMIc2004973

[6] World Health Organization. Laboratory testing for coronavirus disease 2019 (COVID-19) in suspected human cases, interim guidance [Internet]. WHO; 2020. Available from: https://apps.who.int/iris/handle/10665/331329

[7] Grinberg M. Flask web development: developing web applications with python. Second Ed. California: O'Reilly Media; 2018. 233p.

[8] Cerquitelli T, Di Corso E, Proto S, Capozzoli A, Bellotti F, Cassese MG, Baralis E, Mellia M, Casagrande S, Tamburini M. Exploring energy performance certificates through visualization. In EDBT/ ICDT 2019 Joint Conference. Lisbon: EDBT/ICDT; 2019. https://doi.org/11583/2734573 